Article

\title{
Sesquiterpene and Acetogenin Derivatives from the Marine Red Alga Laurencia okamurai
}

\author{
Yi Liang, Xiao-Ming Li, Chuan-Ming Cui, Chun-Shun Li, Hong Sun and Bin-Gui Wang * \\ Key Laboratory of Experimental Marine Biology, Institute of Oceanology, Chinese Academy of \\ Sciences, Nanhai Road 7, Qingdao 266071, China; E-Mails: liangyi1984@126.com (Y.L.); \\ lixmqd@yahoo.com.cn (X.-M.L.); chuanming-cui@163.com (C.-M.C.); \\ lichunshun@ms.qdio.ac.cn (C.-S.L.); sunhonghappy@yahoo.cn (H.S.) \\ * Author to whom correspondence should be addressed; E-Mail: wangbg@ms.qdio.ac.cn; \\ Tel./Fax: +86-532-82898553.
}

Received: 16 November 2012; in revised form: 8 December 2012 / Accepted: 10 December 2012 / Published: 14 December 2012

\begin{abstract}
In addition to 13 known compounds, four new bisabolane sesquiterpenes, okamurenes A-D (1-4), a new chamigrane derivative, okamurene E (5), and a new $\mathrm{C}_{12}$-acetogenin, okamuragenin (6), were isolated from the marine red alga Laurencia okamurai. The structures of these compounds were determined through detailed spectroscopic analyses. Of these, okamurenes A and B (1 and 2) are the first examples of bromobisabolane sesquiterpenes possessing a phenyl moiety among Laurencia-derived sesquiterpenes, while okamuragenin (6) was the first acetogenin aldehyde possessing a $\mathrm{C}_{12}$-carbon skeleton. Each of the isolated compounds was evaluated for the brine shrimp (Artemia salina) lethal assay and 7-hydroxylaurene displayed potent lethality with $\mathrm{LD}_{50} 1.8 \mu \mathrm{M}$.
\end{abstract}

Keywords: marine alga; Laurencia okamurai; bisabolane sesquiterpene; $\mathrm{C}_{12}$-acetogenin; brine shrimp lethality

\section{Introduction}

Marine red algae of the genus Laurencia are prolific sources of diversified secondary metabolites, predominantly sesquiterpenoids, diterpenoids, and nonterpenoid $\mathrm{C}_{15}$-acetogenins [1]. The red alga Laurencia okamurai, widely distributed along the coast of China, mainly yields sesquiterpenes and $\mathrm{C}_{15}$-acetogenins [2]. These compounds, with structurally diverse skeletons, have attracted much 
attention for total syntheses [3] as well as chemotaxonomic research [4-6]. In the past five years, we have systematically conducted chemical investigation towards eight Laurencia species, which have resulted in the isolation of more than 30 new compounds [2,7-11]. In the course of our phytochemical studies on Laurencia okamurai, a new, rearranged chamigrane sesquiterpene, laurenokamurin, was previously characterized [10]. Continuous effort on the chemical investigation of this algal species collected from Weihai coastline resulted in the isolation and identification of five new sesquiterpenes, okamurenes $\mathrm{A}-\mathrm{E}(\mathbf{1}-\mathbf{5})$, one new $\mathrm{C}_{12}$-acetogenin, okamuragenin (6) (Figure 1), as well as nine known sesquiterpenes and four known $\mathrm{C}_{15}$-acetogenins. We present herein the isolation, structure elucidation, and bioactivity of these compounds.

Figure 1. Structures of the isolated new compounds 1-6 from L. okamurai.

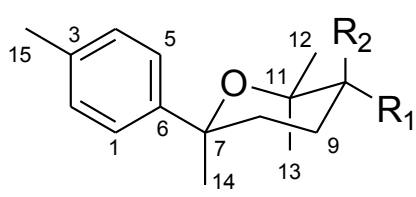

$1 \mathrm{R}_{1}=\mathrm{H}, \mathrm{R}_{2}=\mathrm{Br}$

$2 \mathrm{R}_{1}=\mathrm{Br}, \mathrm{R}_{2}=\mathrm{H}$

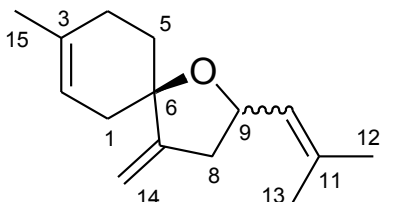

$39 \alpha$ configuration $49 \beta$ configuration

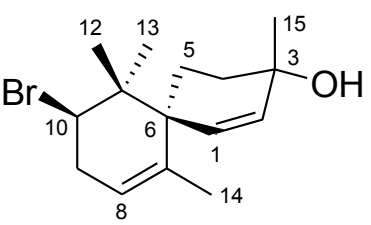

5

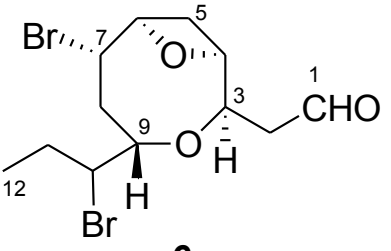

6

\section{Results and Discussion}

\section{Structure Elucidation of the New Compounds}

Okamurene A (1) was obtained as a colorless oil and its molecular formula was established by HRESIMS to be $\mathrm{C}_{15} \mathrm{H}_{21} \mathrm{BrO}$, corresponding to five degrees of unsaturation. The ${ }^{1} \mathrm{H}$ NMR spectrum of 1 (Table 1) exhibited resonances for a para-substituted phenyl unit, four methyl groups, and a brominated or oxygenated methine group. There were also four signals for two diastereotopic methylene protons. The ${ }^{13} \mathrm{C}$ NMR and DEPT spectroscopic data (Table 1) revealed the presence of 15 carbon signals including six aromatic carbons (corresponding to a para-substituted phenyl unit) and nine aliphatic carbons (corresponding to four methyls, two methylenes, one brominated methine, and two oxygenated quaternary carbons). These units accounted for 4 degrees of unsaturation, requiring one additional ring to be present in $\mathbf{1}$.

Table 1. ${ }^{1} \mathrm{H}$ - and ${ }^{13} \mathrm{C}-\mathrm{NMR}$ data of compounds $\mathbf{1}$ and $\mathbf{2}$ in $\mathrm{CDCl}_{3}{ }^{\mathrm{a}}$.

\begin{tabular}{ccccc}
\hline \multirow{2}{*}{ No. } & \multicolumn{1}{c}{$\mathbf{1}\left(\mathbf{C D C l}_{\mathbf{3}}\right)$} & \multicolumn{2}{c}{$\mathbf{2}$} \\
\cline { 2 - 5 } & $\boldsymbol{\delta}_{\mathbf{H}}(\boldsymbol{J}$ in $\mathbf{H z})$ & $\boldsymbol{\delta}_{\mathbf{C}}$ & $\boldsymbol{\delta}_{\mathbf{H}}(\boldsymbol{J}$ in $\mathbf{H z})$ & $\boldsymbol{\delta}_{\mathbf{C}}$ \\
\hline $1 / 5$ & $7.34, \mathrm{~d}(8.0)$ & $124.8, \mathrm{CH}$ & $7.34, \mathrm{~d}(8.1)$ & $126.0, \mathrm{CH}$ \\
$2 / 4$ & $7.11, \mathrm{~d}(8.0)$ & $128.7, \mathrm{CH}$ & $7.12, \mathrm{~d}(8.1)$ & $128.6, \mathrm{CH}$ \\
3 & & $136.1, \mathrm{C}$ & & $136.4, \mathrm{C}$ \\
6 & & $146.0, \mathrm{C}$ & & $143.2, \mathrm{C}$ \\
7 & & $74.6, \mathrm{C}$ & & $74.4, \mathrm{C}$ \\
$8_{\mathrm{eq}}$ & $2.16, \mathrm{~m}$ & $34.1, \mathrm{CH}_{2}$ & $2.56, \mathrm{~m}$ & $36.0, \mathrm{CH}_{2}$ \\
$8_{\mathrm{ax}}$ & $2.10, \mathrm{~m}$ & & $2.18, \mathrm{~m}$ & \\
$9_{\mathrm{eq}}$ & $2.28, \mathrm{~m}$ & $28.2, \mathrm{CH}_{2}$ & $2.27, \mathrm{~m}$ & $29.4, \mathrm{CH}_{2}$ \\
$9_{\mathrm{ax}}$ & $2.25, \mathrm{~m}$ & & $1.82, \mathrm{~m}$ & \\
\hline
\end{tabular}


Table 1. Cont.

\begin{tabular}{lcccc}
\hline 10 & $4.05, \mathrm{dd}(7.9,4.4)$ & $59.1, \mathrm{CH}$ & $4.04, \mathrm{dd}(12.1,4.1)$ & $59.0, \mathrm{CH}$ \\
11 & & $75.2, \mathrm{C}$ & & $76.4, \mathrm{C}$ \\
12 & $1.47, \mathrm{~s}$ & $27.8, \mathrm{CH}_{3}$ & $1.35, \mathrm{~s}$ & $22.5, \mathrm{CH}_{3}$ \\
13 & $1.14, \mathrm{~s}$ & $29.4, \mathrm{CH}_{3}$ & $0.78, \mathrm{~s}$ & $30.8, \mathrm{CH}_{3}$ \\
14 & $1.50, \mathrm{~s}$ & $31.8, \mathrm{CH}_{3}$ & $1.36, \mathrm{~s}$ & $35.8, \mathrm{CH}_{3}$ \\
15 & $2.23, \mathrm{~s}$ & $20.9, \mathrm{CH}_{3}$ & $2.34, \mathrm{~s}$ & $21.0, \mathrm{CH}_{3}$ \\
\hline
\end{tabular}

${ }^{\mathrm{a}}$ Measured at $500 \mathrm{MHz}$ for ${ }^{1} \mathrm{H}$ and $125 \mathrm{MHz}$ for ${ }^{13} \mathrm{C}$.

The structure of the non-phenyl portion of 1 was determined by analysis of 2D NMR data $\left({ }^{1} \mathrm{H}-{ }^{1} \mathrm{H}\right.$ COSY, HSQC, and HMBC). The ${ }^{1} \mathrm{H}-{ }^{1} \mathrm{H}$ COSY experiment established the connectivity for a $-\mathrm{CH}_{2}-\mathrm{CH}_{2}-\mathrm{CH}-$ unit (C-8 through $\mathrm{C}-10$, Figure 2). The $\mathrm{C}-10$ methine of this unit was connected to $\mathrm{CH}_{3}-12$ and $\mathrm{CH}_{3}-13$ via the oxygenated quaternary carbon $\mathrm{C}-11\left(\delta_{\mathrm{C}} 75.2\right)$ as evidenced by the observed HMBC correlations from the methyl protons $\mathrm{H}_{3}-12$ and $\mathrm{H}_{3}-13$ to $\mathrm{C}-10$ and $\mathrm{C}-11$, while the C-8 methylene was linked to the $\mathrm{CH}_{3}-14$ via the oxygenated quaternary carbon $\mathrm{C}-7\left(\delta_{\mathrm{C}} 74.6\right)$ as supported by the observed $\mathrm{HMBC}$ correlation from the methyl protons $\mathrm{H}_{3}-14$ to $\mathrm{C}-8$ (Figure 2). Given the fact that only one oxygen atom existed in the structure, the linkage of $\mathrm{C}-7 / \mathrm{O} / \mathrm{C}-11$ could be constructed, leading to the formation of a tetrahydropyran moiety, which accounted for the remaining degree of unsaturation. Thus, the planar structure of $\mathbf{1}$ was assigned.

Figure 2. Key COSY (bold lines) and HMBC (arrows) correlations for compounds 1, 3/4,

5 , and 6.

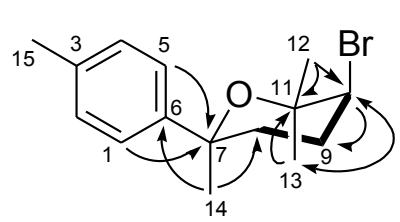

1

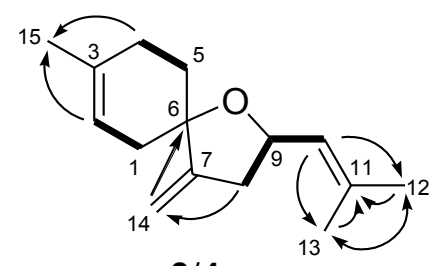

$3 / 4$

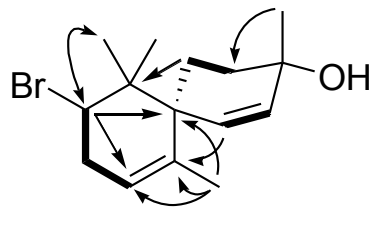

5

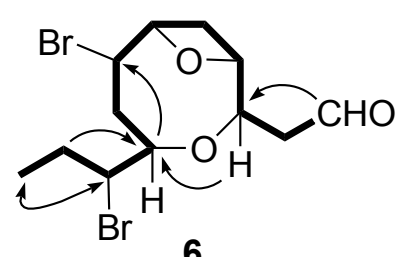

6

Analysis of the proton coupling constants and NOESY data enabled assignment of the relative configuration of $\mathbf{1}$. The appearance of the bromomethine proton $\mathrm{H}-10$ as a double doublet, with coupling constants of 7.9 and $4.4 \mathrm{~Hz}$, suggesting the equatorial orientation of $\mathrm{H}-10$ for $\mathbf{1}$. In the NOESY spectrum, NOE correlations of $\mathrm{H}_{3}-13$ with both $\mathrm{H}-10$ and $\mathrm{H}_{3}-14$ placed the methyl groups $\mathrm{CH}_{3}-13$ and $\mathrm{CH}_{3}-14$ on the same face (axial or pseudoaxial) of the tetrahydropyran ring (Figure 3). On the basis of the above evidence, the structure of $\mathbf{1}$ was determined, and the trivial name okamurene $\mathrm{A}$ was assigned.

Figure 3. Key NOESY correlations for compounds 1 and 2.

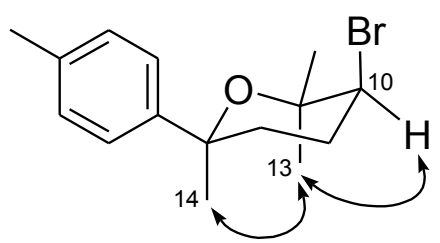

1

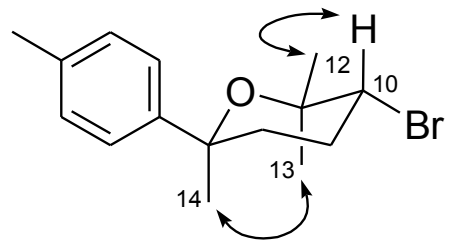

2 
The ${ }^{1} \mathrm{H}$ and ${ }^{13} \mathrm{C}$ NMR spectroscopic data of okamurene B (2), an isomer of $\mathbf{1}$ as established by HRESIMS data, were very similar to those of $\mathbf{1}$ except for some chemical shift variations of signals corresponding to the C-8, C-9, and C-12 through C-14 (Table 1). Therefore, compound 2 was presumed to be a stereoisomer of 1 . Detailed analysis of the ${ }^{1} \mathrm{H}$ and ${ }^{13} \mathrm{C}$ NMR data as well as ${ }^{1} \mathrm{H}-{ }^{1} \mathrm{H}$ COSY and HMBC correlations supported the conclusion that $\mathbf{2}$ possesses the same planar structure as 1. However, comparisons of the $J$-value and NOESY data of $\mathbf{2}$ with those of $\mathbf{1}$ revealed a difference in relative configuration at C-10. A trans-diaxial $J$-value for $\mathrm{H}_{\mathrm{ax}}-10$ and $\mathrm{H}_{\mathrm{ax}}-9(12.1 \mathrm{~Hz})$ indicated an equatorial orientation for the Br-atom at C-10. The NOE correlation from $\mathrm{H}-10$ to $\mathrm{H}_{3}-12$ in the NOESY spectrum indicated an equatorial face of $\mathrm{CH}_{3}-12$, while the NOE correlation from $\mathrm{H}_{3}-13$ to $\mathrm{H}_{3}-14$ placed these two methyl groups in axial orientation (Figure 3). Based on the above data, the structure of compound $\mathbf{2}$ was identified and it was named okamurene B.

Okamurenes C (3) and D (4) were obtained as a colorless oily mixture in a 2:1 ratio, as indicated by the ${ }^{1} \mathrm{H}$ NMR spectrum. Attempts to separate the mixture by various $\mathrm{CC}$ steps using different solvent systems failed. On the other hand, there is no conjugated system in compounds $\mathbf{3}$ and $\mathbf{4}$, making these compounds unsuitable for HPLC separation using the available UV detector. A similar unseparable mixture containing (9S)- and (9R)-2-bromo-3-chloro-6,9-epoxybisabola-7(14),10-diene from L. saitoi was previously described [11]. Most of the NMR signals for compounds 3 and $\mathbf{4}$ were duplicated or overlapped. By detailed analysis of 1D and 2D NMR data, their structures were determined to be C-9 epimer of 6,9-epoxybisabola-2,7(14),10-triene.

The molecular formula of compounds 3 and 4 were determined to be $\mathrm{C}_{15} \mathrm{H}_{22} \mathrm{O}$ (five degrees of unsaturation) on the basis of HRESIMS data. Examination of the ${ }^{1} \mathrm{H}$ and ${ }^{13} \mathrm{C}$ NMR data (Table 2) revealed that they resembled $9 S$ - and/or 9R-2-bromo-3-chloro-6,9-epoxybisabola-7(14),10-diene [11], except for the presence of signals for a trisubstituted vinyl group at C-2 and, accordingly, the lack of the resonances due to a brominated methine at C-2 and a chlorinated quaternary carbon at C-3 [11]. The chemical shifts for the vinyl carbons at $\delta_{\mathrm{C}} 119.1 / 119.0$ (C-2) and 133.4/133.7 (C-3) as well as for one of the neighboring methylene groups $\mathrm{C}-4\left(\delta_{\mathrm{C}} 27.7 / 28.0\right)$ in the ${ }^{13} \mathrm{C}$ NMR spectrum of $\mathbf{3}$ and $\mathbf{4}$ were very similar to those reported for 8-bromochamigra-1,11(12)-dien-9-ol (with C-2 at $\delta_{\mathrm{C}} 119.4, \mathrm{C}-3$ at $\delta_{\mathrm{C}} 132.9$, and C-4 at $\delta_{\mathrm{C}} 27.5$ ) [12], and these data strongly supported the presence of the trisubstituted vinyl group at $\mathrm{C}-2$ in $\mathbf{3} / \mathbf{4}$. These data indicated that compounds 3 and $\mathbf{4}$ were the dehalogenated derivatives corresponding to $9 S$ - and/or 9R-2-bromo-3-chloro-6,9-epoxybisabola-7(14),10-diene [11]. The ${ }^{1} \mathrm{H}-{ }^{1} \mathrm{H}$ COSY and HMBC correlations (Figure 2) further verified the planar structures of $\mathbf{3} / \mathbf{4}$ to be 6,9-epoxybisabola-2,7(14),10-triene. Assignment of the relative configuration at C-6 by NOESY experiment is not applicable for compounds $\mathbf{3}$ and $\mathbf{4}$ since there is no proton around C-6 in the tetrahydrofuran ring. However, the C-6 relative configuration was tentatively assigned to be the same as that of $9 S$ - and/or $9 R$-2-bromo-3-chloro-6,9-epoxybisabola-7(14),10-diene based on the similar NMR data around the chiral center, as well as on biogenetic consideration [11].

Okamurene E (5), a colorless oil, was shown to have the molecular formula of $\mathrm{C}_{15} \mathrm{H}_{23} \mathrm{BrO}$ by the interpretation of HRESIMS data. The IR absorption at $3401 \mathrm{~cm}^{-1}$ exhibited the presence of a hydroxyl group. The ${ }^{1} \mathrm{H}$ NMR spectrum (Table 2) delineated four methyl singlets, one double doublet ascribable to an oxygenated/halogenated methine, and one multiplet and two doublets attributable to three olefinic protons. The ${ }^{13} \mathrm{C}$ and DEPT NMR spectra (Table 2) displayed four methyls, three methylenes, four methines, and four quaternary carbons. Compared to the reported NMR data for 10 -bromo-7 $\alpha$, 
8 $\alpha$-expoxychamigr-1-en-3-ol [12], compound 5 exhibited no resonances for the epoxy moiety in the NMR spectra. Instead, it showed additional signals at $\delta_{\mathrm{H}} 5.23(\mathrm{H}-8)$ and $\delta_{\mathrm{C}} 139.5(\mathrm{C}-7)$ and 120.8 (C-8) for a trisubstituted vinyl group, which was positioned at C-7 based on the observed HMBC correlations from $\mathrm{H}-14$ to $\mathrm{C}-6, \mathrm{C}-7$, and $\mathrm{C}-8$. Further analysis of the ${ }^{1} \mathrm{H}-{ }^{1} \mathrm{H}$ COSY and $\mathrm{HMBC}$ correlations (Figure 2) confirmed the structure of $\mathbf{5}$ as 10-bromo-1,7-chamigradien-3-ol. The relative configurations at C-3, C- 6 , and C-10 of 5 were deduced to be same as those of 10-bromo-7 $\alpha$, $8 \alpha$-expoxychamigr-1-en-3-ol [12] by the NOESY correlation between H-5 and H-10 as well as by their similar NMR data.

Table 2. ${ }^{1} \mathrm{H}$ - and ${ }^{13} \mathrm{C}-\mathrm{NMR}$ data of compounds 3-6 in $\mathrm{CDCl}_{3}{ }^{\mathrm{a}}$.

\begin{tabular}{|c|c|c|c|c|c|c|c|c|}
\hline \multirow{2}{*}{ No. } & \multicolumn{2}{|c|}{3} & \multicolumn{2}{|r|}{4} & \multicolumn{2}{|c|}{5} & \multicolumn{2}{|r|}{6} \\
\hline & $\delta_{\mathrm{H}}(J$ in $\mathrm{Hz})$ & $\delta_{\mathrm{C}}$ & $\delta_{\mathrm{H}}(J$ in $\mathrm{Hz})$ & $\delta_{\mathrm{C}}$ & $\delta_{\mathrm{H}}(J$ in $\mathrm{Hz})$ & $\delta_{\mathrm{C}}$ & $\delta_{\mathrm{H}}(J$ in $\mathrm{Hz})$ & $\delta_{\mathrm{C}}$ \\
\hline 1 & $2.25, \mathrm{~m}$ & $38.1, \mathrm{CH}_{2}$ & $2.18, \mathrm{~m}$ & $36.8, \mathrm{CH}_{2}$ & $5.54, \mathrm{~d}(10.4)$ & 131.2, $\mathrm{CH}$ & 9.80, br s & 199.3, CH \\
\hline $2 \mathrm{a}$ & $5.34, \mathrm{~m}$ & 119.1, CH & $5.34, \mathrm{~m}$ & 119.0, CH & $5.85, \mathrm{~d}(10.4)$ & $136.5, \mathrm{CH}$ & $\begin{array}{c}2.67, \mathrm{dd} \\
(17.5,6.2)\end{array}$ & $42.4, \mathrm{CH}_{2}$ \\
\hline $2 b$ & & & & & & & $\begin{array}{c}3.06, \mathrm{dd} \\
(17.3,7.9)\end{array}$ & \\
\hline 3 & & $133.4, \mathrm{C}$ & & 133.7, C & & $67.4, \mathrm{C}$ & $4.34, \mathrm{t}(6.5)$ & 72.7, $\mathrm{CH}$ \\
\hline $4 a$ & $1.93, \mathrm{~m}$ & 27.7, $\mathrm{CH}_{2}$ & $1.93, \mathrm{~m}$ & 28.0, $\mathrm{CH}_{2}$ & $1.56, \mathrm{~m}$ & 28.5, $\mathrm{CH}_{2}$ & $\begin{array}{l}4.65, \mathrm{dd} \\
(8.7,5.0)\end{array}$ & $81.6, \mathrm{CH}$ \\
\hline $4 b$ & $2.22, \mathrm{~m}$ & & $2.22, \mathrm{~m}$ & & $1.99, \mathrm{~m}$ & & & \\
\hline $5 a$ & $1.58, \mathrm{~m}$ & $31.5, \mathrm{CH}_{2}$ & $1.66, \mathrm{~m}$ & $34.5, \mathrm{CH}_{2}$ & $1.78, \mathrm{~m}$ & $36.3, \mathrm{CH}_{2}$ & $2.75, \mathrm{~m}$ & 21.7, $\mathrm{CH}_{2}$ \\
\hline $5 b$ & $1.82, \mathrm{~m}$ & & $1.75, \mathrm{~m}$ & & & & $2.91, \mathrm{~m}$ & \\
\hline 6 & & $80.9, \mathrm{C}$ & & $80.8, \mathrm{C}$ & & 47.4, C & $4.97, \mathrm{~m}$ & $80.9, \mathrm{CH}$ \\
\hline 7 & & $156.3, \mathrm{C}$ & & $156.5, \mathrm{C}$ & & $139.5, \mathrm{C}$ & $4.21, \mathrm{~m}$ & $50.4, \mathrm{CH}$ \\
\hline $8 \mathrm{a}$ & $2.38, \mathrm{~m}$ & $40.1, \mathrm{CH}_{2}$ & $2.38, \mathrm{~m}$ & $40.3, \mathrm{CH}_{2}$ & $5.23, \mathrm{~m}$ & $120.8, \mathrm{CH}$ & $\begin{array}{c}2.42, \mathrm{dd} \\
(14.1,5.8)\end{array}$ & $41.7, \mathrm{CH}_{2}$ \\
\hline $8 b$ & $\begin{array}{c}2.71, \mathrm{dd} \\
(15.7,9.7)\end{array}$ & & $\begin{array}{c}2.61, \mathrm{dd} \\
(15.6,9.5)\end{array}$ & & & & $2.61, \mathrm{~m}$ & \\
\hline 9 & $4.63, \mathrm{~m}$ & $71.8, \mathrm{CH}$ & $4.63, \mathrm{~m}$ & $72.8, \mathrm{CH}$ & $2.58, \mathrm{~m}$ & $36.1, \mathrm{CH}_{2}$ & $\begin{array}{c}4.50, \mathrm{dd} \\
(7.4,3.5)\end{array}$ & $74.4, \mathrm{CH}$ \\
\hline 10 & $5.22, \mathrm{~m}$ & 126.0, CH & $5.22, \mathrm{~m}$ & 126.2, $\mathrm{CH}$ & $\begin{array}{c}4.64, \mathrm{dd} \\
(10.6,6.4)\end{array}$ & $61.4, \mathrm{CH}$ & $\begin{array}{c}3.80, \mathrm{dt} \\
(11.5,3.5)\end{array}$ & $64.1, \mathrm{CH}$ \\
\hline $11 \mathrm{a}$ & & $136.2, \mathrm{C}$ & & $135.5, \mathrm{C}$ & & $41.6, \mathrm{C}$ & $1.77, \mathrm{~m}$ & 27.4, $\mathrm{CH}_{2}$ \\
\hline $11 b$ & & & & & & & $1.88, \mathrm{~m}$ & \\
\hline 12 & $1.69, \mathrm{~s}$ & $18.2, \mathrm{CH}_{3}$ & $1.70, \mathrm{~s}$ & $18.3, \mathrm{CH}_{3}$ & $1.02, \mathrm{~s}$ & $18.1, \mathrm{CH}_{3}$ & $1.07, \mathrm{t}(7.7)$ & $12.8, \mathrm{CH}_{3}$ \\
\hline 13 & $1.71, \mathrm{~s}$ & $25.8, \mathrm{CH}_{3}$ & $1.71, \mathrm{~s}$ & $25.8, \mathrm{CH}_{3}$ & $1.11, \mathrm{~s}$ & $26.3, \mathrm{CH}_{3}$ & & \\
\hline $14 \mathrm{a}$ & 4.78, br s & $103.5, \mathrm{CH}_{2}$ & 4.78, br s & $103.8, \mathrm{CH}_{2}$ & $1.57, \mathrm{~s}$ & $21.9, \mathrm{CH}_{3}$ & & \\
\hline $14 b$ & 4.90 , br s & & 4.91, br s & & & & & \\
\hline 15 & $1.66, \mathrm{~s}$ & $23.4, \mathrm{CH}_{3}$ & $1.66, \mathrm{~s}$ & $23.4, \mathrm{CH}_{3}$ & $1.31, \mathrm{~s}$ & $28.8, \mathrm{CH}_{3}$ & & \\
\hline
\end{tabular}

Okamuragenin (6), isolated as a colorless oil, was assigned the molecular formula $\mathrm{C}_{12} \mathrm{H}_{18} \mathrm{Br}_{2} \mathrm{O}_{3}$ on the basis of HRESIMS, consistent with three degrees of unsaturation. The IR spectrum exhibited strong absorptions at 2762 and $1728 \mathrm{~cm}^{-1}$, indicating the existence of an aldehyde group. In accordance with the IR signals, the ${ }^{1} \mathrm{H}$ and ${ }^{13} \mathrm{C}$ NMR data (Table 2) also indicated the presence of an aldehyde group at $\delta_{\mathrm{H}}(9.80, \mathrm{H}-1)$ and $\delta_{\mathrm{C}} 199.3(\mathrm{CH}, \mathrm{C}-1)$. The ${ }^{1} \mathrm{H}-{ }^{1} \mathrm{H}$ COSY spectrum revealed that the aldehyde 
group was extended to a straight spin system consisting of six methines, four methylenes, and terminated by a methyl group (Figure 2). Compound 6 was deduced to be bicyclic, since no other unsaturated functionalities were indicated by the NMR data (Table 2). The connectivity of C-3/O/C-9 was deduced by the correlation from H-3 to C-9 in the HMBC spectrum (Figure 2). Taking into account the downfield chemical shifts of C-4 $\left(\delta_{\mathrm{C}} 81.6\right)$ and C-6 $\left(\delta_{\mathrm{C}} 80.9\right)$ and the calculated 3 degrees of unsaturation, C-4 and C-6 had to be linked through an oxygen atom. Finally, the two remaining Br-atoms indicated by the molecular formula could only be located at C-7 and C-10 based on the chemical shifts [13]. The relative configuration was determined by NOESY experiment. The same orientation of $\mathrm{CH}_{2}-2, \mathrm{H}-4$, and $\mathrm{H}-9$ was evidenced by the NOE correlations of $\mathrm{H}-2$ to $\mathrm{H}-4$ and $\mathrm{H}-9$, while H-9 was syn to H-7 based on the NOE correlation between them. The above data established the structure of 6 , trivially named okamuragenin.

In addition to the six new compounds, the other nine sesquiterpenes including isobromocuparene [14], 7-hydroxylaurene [15], laurene [16], filiformin [17], debromofiliformin [18], 6-bromo-filiformin [19], deoxyprepacifenol [20], 2-bromo-3-chloro-2,7-epoxy-9-chamigren-8 $\alpha$-ol [11], and 2,10-dibromo-3chloro-7-chamigren-9-ol [21], together with four $\mathrm{C}_{15}$-acetogenins including $3 E$, 12Z-laurediol [22], neolaurallene [23], E-stereoisomer of neoisoprelaurefucin [24], and 3Z-laurentin [25], were all identified by comparison of their spectral data with those previously reported.

The isolated compounds were evaluated for the brine shrimp (Artemia salina) lethal activity [26,27]. Among them, 7-hydroxylaurene was found to possess potent lethality with $\mathrm{LD}_{50} 1.8 \mu \mathrm{M}$, which is more active than that of 7-hydroxylaurene acetate, allolaurinterol acetate, and laurene [12]. Analysis of structure-activity relationship showed that the 7-hydroxyl group in laurene sesquiterpenes may play a key role in the brine shrimp toxicity, and the activity reduced significantly after acetylation. The above data suggested that 7-hydroxylaurene may be a potent chemical defensive agent with cytotoxicity, although the hatchability test was not performed [27]. The other tested compounds only displayed moderate or weak activity (data not shown).

\section{Experimental Section}

\subsection{General}

IR spectra were measured on a Nicolet NEXUS 470 FT-IR spectrophotometer. Optical rotations were recorded on an Atago Polax-L polarimeter. UV spectra were determined on a Spectrumlab 54 UV-visible spectrophotometer. HRESIMS were run on a VG Autospec 3000 mass spectrometer. 1D and 2D NMR spectra were obtained at 500 and $125 \mathrm{MHz}$ for ${ }^{1} \mathrm{H}$ and ${ }^{13} \mathrm{C}$, respectively, on a Bruker Advance $500 \mathrm{MHz}$ NMR spectrometer in $\mathrm{CDCl}_{3}$ with $\mathrm{TMS}$ as internal standard. Column chromatography (CC) was performed on Si gel (200-300 mesh, Qingdao Haiyang Chemical Co., Qingdao, China) and Sephadex LH-20 (Sigma). TLC was carried out with precoated Si gel plates (GF-254, Qingdao Haiyang Chemical Co., Qingdao, China).

\subsection{Algal Material}

The marine red alga Laurencia okamurai Yamada was collected along Weihai coastline in Shandong Province, China, in May, 2007, and was identified by B.-M. Xia, Institute of Oceanology, 
Chinese Academy of Sciences (IOCAS). A voucher specimen (HZ0705) has been deposited at the Key Laboratory of Experimental Marine Biology of IOCAS.

\subsection{Extraction and Isolation}

The dried and powdered alga L. okamurai $(3.8 \mathrm{~kg})$ was extracted with a mixture of $\mathrm{CHCl}_{3}$ and $\mathrm{MeOH}(1: 1, \mathrm{v} / \mathrm{v})$. The concentrated extracts were partitioned between $\mathrm{H}_{2} \mathrm{O}$ and EtOAc. The EtOAc-soluble fraction was loaded to Si gel column, eluting with a step gradient of increasing EtOAc $(0 \%-100 \%)$ in petroleum ether (PE) to give eight fractions I-VIII. Fraction II eluted with PE/EtOAc 100:1 and was further purified by preparative TLC to afford a mixture of $\mathbf{3}$ and $\mathbf{4}$ (5.6 mg). Fraction IV eluted with PE/acetone 100:1 and was further separated by preparative TLC to afford 1 (3.7 mg), 2 (4.7 mg), 6 (13.1 mg). Fraction VI eluted with PE/acetone 30:1 and was further separated by Sephadex LH-20 (MeOH) CC and preparative TLC to afford $5(10.7 \mathrm{mg})$.

\subsection{Computational Details}

Okamurene A (1): Colorless oil; $[\alpha]^{18}{ }_{\mathrm{D}}+2.3$ (c $\left.0.11, \mathrm{MeOH}\right) ; \mathrm{UV}(\mathrm{MeOH}) \lambda_{\max }(\log \varepsilon)$ 221 (3.56) nm; IR (KBr) $v_{\max } 3065,2964,2857,1514,1479$, and $1205 \mathrm{~cm}^{-1} ;{ }^{1} \mathrm{H}$ and ${ }^{13} \mathrm{C}$ NMR data, see Table 1; HRESIMS $m / z 297.0748[\mathrm{M}+\mathrm{H}]^{+}$(calcd for $\mathrm{C}_{15} \mathrm{H}_{22}{ }^{79} \mathrm{BrO}, 297.0854$ ).

Okamurene B (2): Colorless oil; $[\alpha]^{18}{ }_{\mathrm{D}}+3.6$ (c $\left.0.06, \mathrm{MeOH}\right) ; \mathrm{UV}(\mathrm{MeOH}) \lambda_{\max }(\log \varepsilon)$ 221 (3.66) nm; IR (KBr) $v_{\max } 3068,2964,2857,1514,1477$, and $1208 \mathrm{~cm}^{-1} ;{ }^{1} \mathrm{H}$ and ${ }^{13} \mathrm{C}$ NMR data, see Table 1; HRESIMS $m / z 319.0726[\mathrm{M}+\mathrm{Na}]^{+}$(calcd for $\mathrm{C}_{15} \mathrm{H}_{21} \mathrm{BrONa}, 319.0673$ ).

Okamurenes C (3) and D (4): Colorless oil; IR (KBr) $v_{\max } 3096,2924,2854,1637$, 1457, and $1024 \mathrm{~cm}^{-1}$; ${ }^{1} \mathrm{H}$ and ${ }^{13} \mathrm{C}$ NMR data, see Table 2; HRESIMS $\mathrm{m} / z 219.1757[\mathrm{M}+\mathrm{H}]^{+}$(calcd for $\left.\mathrm{C}_{15} \mathrm{H}_{23} \mathrm{O}, 219.1749\right)$.

Okamurene E (5): Colorless oil; $[\alpha]^{18}{ }_{\mathrm{D}}+7.6$ (c 0.09, MeOH); IR (KBr) v $v_{\max }$ 3401, 2971, 2928, 1549, 1447, 1367 and $1121 \mathrm{~cm}^{-1} ;{ }^{1} \mathrm{H}$ and ${ }^{13} \mathrm{C}$ NMR data, see Table 2; HRESIMS $m / z 281.0846\left[\mathrm{M}-\mathrm{H}_{2} \mathrm{O}+\mathrm{H}\right]^{+}$ (calcd for $\mathrm{C}_{15} \mathrm{H}_{22}{ }^{79} \mathrm{Br}, 281.0905$ ), and 283.0860 [M- $\left.\mathrm{H}_{2} \mathrm{O}+\mathrm{H}\right]^{+}$(calcd for $\mathrm{C}_{15} \mathrm{H}_{22}{ }^{81} \mathrm{Br}$, 283.0884).

Okamuragenin (6): Colorless oil; $[\alpha]^{18}+11.2$ (c 0.18, MeOH); IR (KBr) $v_{\max } 3060,2926$, 2854, 2762, 1728, 1421, and $1134 \mathrm{~cm}^{-1} ;{ }^{1} \mathrm{H}$ and ${ }^{13} \mathrm{C}$ NMR data, see Table 2; HRESIMS $m / z 385.9926\left[\mathrm{M}+\mathrm{NH}_{4}\right]^{+}$(calcd for $\mathrm{C}_{12} \mathrm{H}_{22} \mathrm{~N}^{79} \mathrm{Br}_{2} \mathrm{O}_{3}, 385.9966$ ), $387.9986\left[\mathrm{M}+\mathrm{NH}_{4}\right]^{+}$(calcd for $\left.\mathrm{C}_{12} \mathrm{H}_{22} \mathrm{~N}^{79} \mathrm{Br}^{81} \mathrm{BrO}_{3}, 387.9946\right)$.

\subsection{Brine Shrimp Toxicity}

Brine shrimp (Artemia salina) toxicity of crude extract and pure compounds was determined as detailed previously $[26,27]$.

\section{Conclusions}

Four new bisabolane sesquiterpenes, okamurenes A-D (1-4), a new chamigrane derivative, okamurene $\mathrm{E}(\mathbf{5})$, and a new $\mathrm{C}_{12}$-acetogenin, okamuragenin (6), together with 13 known related metabolites, were isolated from the marine red alga L. okamurai. Among them, okamurenes A and B 
(1 and 2) are first examples of bromobisabolane sesquiterpenes possessing a phenyl moiety among Laurencia-derived sesquiterpenes, while okamuragenin (6) was the first acetogenin aldehyde possessing a $\mathrm{C}_{12}$-carbon skeleton. Each of the isolated compounds was evaluated for the brine shrimp (Artemia salina) lethal assay and 7-hydroxylaurene displayed potent lethality with $\mathrm{LD}_{50} 1.8 \mu \mathrm{M}$.

\section{Acknowledgments}

Financial support from the Natural Science Foundation of China (30530080 and 31270403), from the National Marine 863 Project (2007AA09Z403), and from the Department of Science and Technology of Shandong Province (2006GG2205023) is gratefully acknowledged. The authors are grateful to B.-M. Xia at the Institute of Oceanology, Chinese Academy of Sciences, for identifying the plant material and to N.-Y. Ji at Yantai Institute of Coastal Zone Research, Chinese Academy of Sciences, for his help during the preparation of the manuscript.

\section{References}

1. Cabrita, M.T.; Vale, C.; Rauter, A.P. Halogenated compounds from marine algae. Mar. Drugs 2010, 8, 2301-2317.

2. Ji, N.-Y.; Li, X.-M.; Zhang, Y.; Wang, B.-G. Two new halogenated chamigrane-type sesquiterpenes and other secondary metabolites from the marine red alga Laurencia okamurai and their chemotaxonomic significance. Biochem. Syst. Ecol. 2007, 35, 627-630.

3. Sugimoto, M.; Suzuki, T.; Hagiwara, H.; Hoshi, T. The first total synthesis of $(+)-(Z)$-laureatin. Tetrahedron Lett. 2007, 48, 1109-1112.

4. Faulkner, D.J. Marine natural products. Nat. Prod. Rep. 1996, 13, 75-125.

5. Masuda, M.; Abe, T.; Suzuki, T.; Suzuki, M. Morphological and chemotaxonomic studies on Laurencia composita and L. okamurae (Ceramiales, Rhodophyta). Phycologia 1996, 35, 550-562.

6. Carvalho, L.R.; Fujii, M.T.; Roque, N.F.; Lago, H.G. Aldingenin derivatives from the red alga Laurencia aldingensis. Phytochemistry 2006, 67, 1331-1335.

7. Ji, N.-Y.; Li, X.-M.; Li, K.; Wang, B.-G. Laurendecumallenes A-B and laurendecumenynes A-B, halogenated nonterpenoid $\mathrm{C} 15$-acetogenins from the marine red alga Laurencia decumbens. J. Nat. Prod. 2007, 70, 1499-1502.

8. Ji, N.-Y.; Li, X.-M.; Ding, L.-P.; Wang, B.-G. Diterpenes, sesquiterpenes, and a C15-acetogenin from the marine red alga Laurencia mariannensis. J. Nat. Prod. 2007, 70, 1901-1905.

9. Ji, N.-Y.; Li, X.-M.; Ding, L.-P.; Wang, B.-G. Aristolane sesquiterpenes and highly brominated indoles from the marine red alga Laurencia similis (Rhodomelaceae). Helv. Chim. Acta 2007, 90, 385-391.

10. Liang, Y.; Li, X.M.; Cui, C.M.; Li, C.S.; Wang, B.G. A new rearranged chamigrane sesquiterpene from Laurencia okamurai. Chin. Chem. Lett. 2009, 20, 190-192.

11. Ji, N.-Y.; Li, X.-M.; Li, K.; Wang, B.-G. Halogenated sesquiterpenes from the marine red alga Laurencia saitoi (Rhodomelaceae). Helv. Chim. Acta 2009, 92, 1873-1879.

12. Li, X.-D.; Miao, F.-P.; Li, K.; Ji, N.-Y. Sesquiterpenes and acetogenins from the marine red alga Laurencia okamurai. Fitoterapia 2012, 83, 518-522. 
13. Suzuki, M.; Kurosawa, E. (3E)-Laureatin and (3E)-isolaureatin, halogenated C-15 non-terpenoid compounds from the red alga Laurencia nipponica Yamada. Bull. Chem. Soc. Jpn. 1987, 60, 3791-3792.

14. Wright, A.D.; König, G.M.; De Nys, R.; Sticher, O. Seven new metabolites from the marine red alga Laurencia majuscula. J. Nat. Prod. 1993, 56, 394-401.

15. Wratten, S.J.; Faulkner, D.J. Metabolites of the red alga Laurencia subopposita. J. Org. Chem. 1977, 42, 3343-3349.

16. Irie, T.; Suzuki, T.; Yasunari, Y.; Kurosawa, E. Laurene, a sesquiterpene hydrocarbon from Laurencia species. Tetrahedron 1969, 25, 459-468.

17. Kazlauskas, R.; Murphy, P.T.; Quinn, R.J.; Wells, R.J. New laurene derivatives from Laurencia filiformis. Aust. J. Chem. 1976, 29, 2533-2539.

18. Nemoto, H.; Miyata, J.; Hakamata, H.; Nagamochi, M.; Fukumoto, K. A novel and efficient route to chiral A-ring aromatic trichothecanes-The first enantiocontrolled total synthesis of (-)-debromofiliformin and (-)-filiformin. Tetrahedron 1995, 51, 5511-5522.

19. Suzuki, M.; Kurosawa, E. Halogenated sesquiterpene phenols and ethers from the red alga Laurencia glandulifera Kutzing. Bull. Chem. Soc. Jpn. 1979, 52, 3349-3351.

20. De Nys, R.; Coll, J.C.; Bowden, B.F. Tropical marine algae. IX. A new sesquiterpenoid metabolite from the red alga Laurencia rnarianensis. Aust. J. Chem. 1993, 46, 933-937.

21. Suzuki, M.; Kurosawa, E.; Furusaki, A. The structure and absolute stereochemistry of a Halogenated chamigrene derivative from the red alga Laurencia species. Bull. Chem. Soc. Jpn. 1988, 61, 3371-3373.

22. Fukuzawa, A.; Honma, T.; Takasugi, Y.; Murai, A. Biogenetic intermediates, $(3 E$ and $3 Z, 12 Z)$-laurediols and (3E and 3Z)-12,13-dihydrolaurediols, isolated from Laurencia nipponica. Phytochemistry 1993, 32, 1435-1438.

23. Suzuki, M.; Kurosawa, E.; Furusaki, A.; Katsuragi, S. Neolaurallene, a new halogenated C-15 nonterpenoid from the red alga Laurencia okamurai Yamada. Chem. Lett. 1984, 1033-1034.

24. Aydoğmuş, Z.; Imre, S.; Ersoy, L.; Wray, V. Halogenated secondary metabolites from Laurencia obtusa. Nat. Prod. Res. 2004, 18, 43-49.

25. Irie, T.; Izawa, M.; Kurosawa, E. Laureatin, a constituent from Laurencia nipponica Yamada. Tetrahedron Lett. 1968, 24, 2091-2096.

26. Gerwick, W.H.; Proteau, P.J.; Nagle, D.G.; Hamel, E.; Blokhin, A.; Slate, D. Structure of curacin A, a novel antimitotic, antiproliferative, and brine shrimp toxic natural product from the marine Cyanobacterium Lyngbya majuscule. J. Org. Chem. 1994, 59, 1243-1245.

27. Carballo, J.L.; Hernández-Inda, Z.L.; Pérez, P.; García-Grávalos, M.D. A comparison between two brine shrimp assays to detect in vitro cytotoxicity in marine natural products. $B M C$ Biotechnol. 2002, 2, 17.

(C) 2012 by the authors; licensee MDPI, Basel, Switzerland. This article is an open access article distributed under the terms and conditions of the Creative Commons Attribution license (http://creativecommons.org/licenses/by/3.0/). 